\title{
Production of oxidants in alveolar macrophages and blood leukocytes
}

\author{
T.S. Haugen*, O.H. Skjønsberg**, H. Kähler*, T. Lyberg*
}

Production of oxidants in alveolar macrophages and blood leukocytes. T.S. Haugen, O.H. Skjønsberg, H. Kähler, T. Lyberg. (C) ERS Journals Ltd 1999.

ABSTRACT: Increased production of oxidants subsequent to phagocyte stimulation has been associated with tissue damage in lung inflammatory disorders. The overall oxidative burden of the lung may vary with inflammatory cell composition.

Flow cytometry using three different dyes, dihydroethidium (DHE), dichlorofluorescein diacetate (DCFH-DA) and dihydrorhodamine 123 (DHR), all compounds that by interaction with oxidants are transformed to fluorescent products, was used to examine the production of intracellular oxidants in alveolar macrophages (AMs), including size-defined subpopulations, monocytes (Ms) and polymorphonuclear neutrophils (PMNs) during in vitro incubation in the presence or absence of phorbol myristate acetate (PMA).

PMA stimulation led to slightly increased (two-fold) $(p<0.05)$ DHE-induced fluorescence in AMs, whereas it was greatly increased in Ms and PMNs (13-fold and 113-fold, respectively). The levels of DCFH-DA- and DHR-induced fluorescence were significantly $(\mathbf{p}<0.05)$ increased (four-fold and 110 -fold, respectively) by PMA stimulation of PMNs, but not of AMs and Ms. Significant differences $(p<0.05)$ in the levels of DHE- and DCFH-DA-induced fluorescence in small and large AMs were also demonstrated.

The results show that the potential to increase the generation of various oxidants upon stimulation was: PMNs $>$ Ms $>$ AMs, suggesting that the total oxidative burden of the lungs is dependent on the type of inflammatory cells present, as well as on their state of activation.

Eur Respir J 1999; 14: 1100-1105.
*Research Forum and **Dept of Pulmonary Medicine, Ullevaal University Hospital, Oslo, Norway.

Correspondence: T.S. Haugen, Research Forum (FUS), Ullevaal University Hospital, N-0407 Oslo, Norway. Fax: 47 22026811

Keywords: Alveolar macrophages monocytes

oxidants

polymorphonuclear neutrophils

Received: December 311998

Accepted after revision June 201999
Oxidants, counterbalanced by the antioxidant system, are a prerequisite in the antimicrobial and antitumour defence mechanisms of the lung $[1,2]$. However, excessive production of oxidants may lead to oxidative damage to the tissue [3,4], and involvement of oxidants has been associated with a number of pulmonary diseases, such as adult respiratory distress syndrome (ARDS), idiopathic pulmonary fibrosis (IPF), sarcoidosis and asthma [5-8].

Upon activation, a burst of oxygen consumption (respiratory burst) occurs in inflammatory cells as a result of the catalytic action of the enzyme reduced nicotinamide adenine dinucleotide phosphate oxidase. In this process, the superoxide anion $\left(\mathrm{O}_{2}{ }^{-}\right)$is produced $[3,4]$. The $\mathrm{O}_{2}{ }^{-}$formed can be rapidly converted to hydrogen peroxide, hypochlorous acid (formed from $\mathrm{H}_{2} \mathrm{O}_{2}$ and chloride ions by myeloperoxidase released from neutrophil granules), hydroxyl radical $(\cdot \mathrm{OH})$ and other toxic species, which collectively are termed reactive oxygen species (ROS) [5]. These are regarded as the most important biologically active oxidants and are responsible for injury to microorganisms and the surrounding tissue. Closely related to $\mathrm{O} \cdot{ }_{2}^{-}$is the powerful oxidant peroxynitrite $\left(\mathrm{ONOO}^{-}\right)$, generated through the interaction of $\mathrm{O}_{2}{ }^{-}$with nitric oxide (NO-) [9]. The major result of the reaction of $\mathrm{ONOO}^{-}$with pro- teins is the addition of a nitro group in the ortho position of tyrosine residues to form nitrotyrosine [10]. The presence of nitrotyrosine has frequently been suggested as a marker of peroxynitrite-dependent damage in vivo, and has been detected immunohistochemically in human acute lung injury $[11,12]$, as well as in ischaemic rat lung injury [13].

Alveolar macrophages (AMs) are believed to be the main source of oxidants in the healthy lung, but, in inflammatory disorders, invading blood phagocytes like monocytes (Ms) and polymorphonuclear neutrophils (PMNs) contribute significantly to the oxidative burden $[2,3]$. In addition to increased influx of blood leukocytes, changes in AM maturity may occur $[14,15]$, associated with changes in cell size, density and functional properties [16-18]. Thus, the predominant inflammatory cell population of the lung has been reported to vary according to the character of the disease $[14,15,19-21]$. Consequently, the overall oxidative burden of the lung may be dependent not only on the cell activation state but also on the inflammatory cell composition and the ability of the involved cells to produce oxidants. Therefore, the capacity for intracellular production of oxidants in AMs, inclucluding size-defined subpopulations, Ms and PMNs from healthy volunteers during in vitro incubation and phorbol 
myristate acetate (PMA) stimulation was examined using three different oxidant-sensitive fluorescent probes.

\section{Materials and methods}

\section{Study population}

Bronchoalveolar lavage (BAL) was performed in six healthy nonsmokers, four males and two females; mean age 27 yrs (range 24-36). Citrated blood samples for the analyses of Ms and PMNs were taken simultaneously from the same individuals. The participants all had normal lung function (spirometry) and used no medication. Informed consent was given and the study approved by the Regional Ethics Committee.

\section{Bronchoalveolar lavage procedure}

After premedication $(0.6 \mathrm{mg}$ intramuscular atropine and $10 \mathrm{mg}$ hydrokon bitartrate perorally) and local anaesthesia via inhalation of atomized lignocaine, a fibreoptic bronchoscope (Olympus 30; Olympus Optical Co. Ltd., Tokyo, Japan) was wedged in a segmental bronchus of the middle lobe. BAL was performed using three consecutive $50-\mathrm{mL}$ aliquots of sterile isotonic saline solution $\left(37^{\circ} \mathrm{C}\right)$, which was recovered by gentle suction and thereafter immediately cooled on crushed ice.

\section{Lung alveolar macrophage preparations}

After filtering the lavage fluid through one-layered sterile gauze, cytocentrifuge preparations (Cytospin; Shandon, Runcorn, UK) were stained using a modified May-Grünwald Giemsa method (Diff Quick; Dade, Dade Diagnostika, Munich, Germany) for differential cell counting. Total cell counts (Bürker haemocytometer Assistent, Germany) and viability (trypan blue exclusion test) were assessed after centrifugation $\left(822 \times \mathrm{g}, 7 \mathrm{~min}, 4^{\circ} \mathrm{C}\right)$ and resuspension of bronchoalveolar cells in phosphate-buffered saline (PBS; $0.01 \mathrm{M}$ phosphate buffer, $0.0027 \mathrm{M} \mathrm{KCl}, 0.137 \mathrm{M} \mathrm{NaCl}$, $\mathrm{pH}$ 7.4). The cells were washed twice $(300 \times g$ for $5 \mathrm{~min})$ in PBS and finally resuspended in basic cell culture medium supplemented with $20 \%$ heat-inactivated $\left(56^{\circ} \mathrm{C}, 30 \mathrm{~min}\right)$ foetal calf serum (BioWittaker, Walkersville, ML, USA). The basic tissue culture medium used was endotoxin-free $\left(<50 \mathrm{pg} \cdot \mathrm{mL}^{-1}\right)$ RPMI 1640 from Gibco-Biocult (Paisley, UK).

Cell culture conditions and preparation for flow cytometry

AM suspensions $\left(1.6 \pm 0.6 \times 10^{6}\right.$ cells $\left.\cdot \mathrm{mL}^{-1}\right)$ and citrated whole blood were incubated in polystyrene tubes equipped with ventilation caps in the presence or absence of PMA $\left(100 \mathrm{ng} \cdot \mathrm{mL}^{-1}\right)$ (Sigma, St Louis, MO, USA) for up to $24 \mathrm{~h}$ at $37^{\circ} \mathrm{C}\left(5 \% \mathrm{CO}_{2}\right.$ in humidified air). Samples of AMs and whole blood were withdrawn for flow cytometric analysis of oxidants after $0,0.5,1,2,4$ and $24 \mathrm{~h}$.

After each incubation time $100 \mu \mathrm{L}$ of AM suspension $\left(1.6 \pm 0.6 \times 10^{5}\right.$ cells $)$ and $50 \mu \mathrm{L}$ of whole blood were incubated with $10 \mu \mathrm{L}$ of dihydroethidium (DHE) (Sigma), 2,7-dichlorofluorescein (DCFH) diacetate (DCFH-DA)
(Sigma) and dihydrorhodamine 123 (DHR) (Molecular Probes, Leiden, the Netherlands) (final concentrations 5 $\mu \mathrm{M})$ for $15 \mathrm{~min}$ at $37^{\circ} \mathrm{C}$ in the dark. Cell suspensions or blood with $10 \mu \mathrm{L}$ PBS served as controls of autofluorescence.

Thereafter, AM suspensions were washed twice with PBS $(2 \mathrm{~mL})$ before cell fixation in $1 \%$ paraformaldehyde (PFA), whereas whole blood was incubated with $1.5 \mathrm{~mL}$ of an erythrocyte-lysing solution $\left(\mathrm{NH}_{4} \mathrm{Cl} 155.5 \mathrm{mM}, \mathrm{NaH}-\right.$ $\mathrm{CO}_{3} 1 \mathrm{mM}$, ethylenediamine tetraacetic acid (EDTA)- $\mathrm{Na}_{3}$ $0.109 \mathrm{mM}$ ) for $15 \mathrm{~min}$ at $18^{\circ} \mathrm{C}$. After centrifugation (300 $\times g, 5 \mathrm{~min}$ ) and washing with $2 \mathrm{~mL}$ PBS, blood leukocytes were fixed in $1 \%$ PFA and like the AMs kept cold $\left(4^{\circ} \mathrm{C}\right)$ and in the dark until flow cytometry was performed, within $24 \mathrm{~h}$.

\section{Flow cytometry}

Nonfluorescent DHE, DCFH (intracellularly transformed intermediate of DCFH-DA) and DHR have been reported to be oxidized within cells to fluorescent products by oxidants [22-24], which enables monitoring of intracellular oxidant generation by measuring cell fluorescence intensity. This was done using a FACSort flow cytometer equipped with a FACStation ${ }^{\mathrm{TM}}$ and Cell Quest ${ }^{\mathrm{TM}}$ software (Becton Dickinson, Rutherford, NJ, USA). Ten-thousand and 5,000 events were registered from each blood and AM sample, respectively. The blood leukocyte subpopulations, i.e. lymphocytes, Ms and $\mathrm{PMNs}$ were separated via electronic gating, using the PC-Lysys 1.0 software program (Becton Dickinson). Comparisons between AM subpopulations of different cell size were carried out by gating into three separate regions, whereby the majority of the cells were within region 2 (intermediate size) (fig. 1). The intensity of the specific fluorescence was calculated and expressed as relative linear median fluorescence intensity (RLMFI), i.e. as the ratio of specific to nonspecific (autofluorescence) linear fluorescence [25, 26].

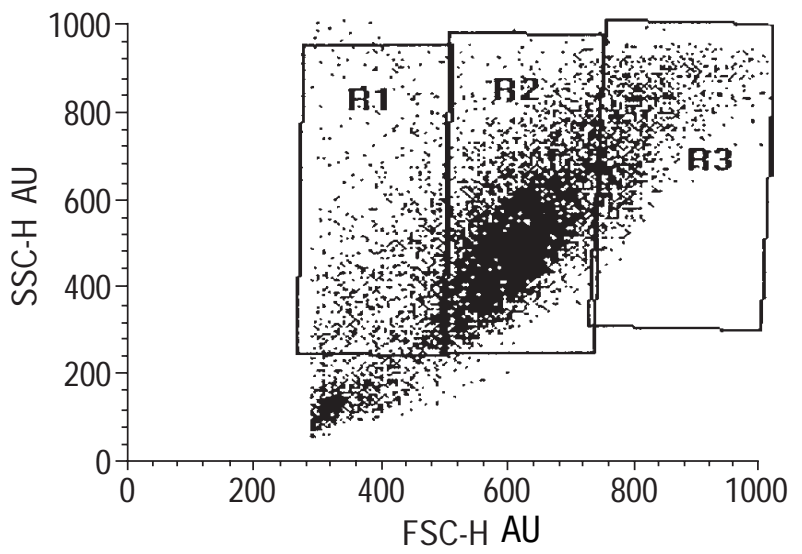

Fig. 1. - Gating of alveolar macrophages (AMs) into subpopulations of different size in a forward (FSC-H)/side scatter (SSC-H) dot plot, in which the abscissa (FSC-H) represents cell size and the ordinate (SSC$\mathrm{H})$ cell granularity. The gates R1, R2 and R3 represent small, intermediate and large AMs, respectively. AU: arbitrary units. 


\section{Statistics}

All data are presented as mean \pm SEM. Statistical analyses were performed using the Wilcoxon signed rank test of paired data and Wilcoxon two-sample rank sum test. Differences were considered significant when $\mathrm{p}<0.05$.

\section{Results}

\section{Recovery and cell distributions}

The recovery of the BAL fluid was $73 \pm 1.5 \%(109 \pm 2.2$ $\mathrm{mL}$ ) of instilled fluid. The total cell count in the recovered lavage fluid was $8.2 \pm 2.9 \times 10^{6}$ cells. Differential cell counts showed $90 \pm 1 \%$ macrophages, and the viability was $89 \pm 3 \%$. The regional distribution of AM was: region 1 (small cells), $13 \pm 2 \%$; region 2 (intermediate cells), $70 \pm 4 \%$ and region 3 (large cells), $15 \pm 1 \%$. The total was not $100 \%$ because of difficulties in performing accurate gating.

Production of oxidants in alveolar macrophages, monocytes and polymorphonuclear neutrophils

PMA stimulation induced a two-fold increase in RLMFI in DHE-incubated AMs (fig. 2), a 13-fold increase in Ms and a 113-fold increase in PMNs, the differences between the cell populations being statistically significant $(\mathrm{p}<0.01)$. The basal RLMFIs were the same in the total populations of AMs, Ms and PMNs throughout $24 \mathrm{~h}$ of unstimulated in vitro incubation.

In DCFH-DA-incubated PMNs (fig. 2), a modestly (four-fold), but significantly $(\mathrm{p}<0.05)$ increased RLMFI was observed following PMA stimulation, whereas no significant changes were seen during $24 \mathrm{~h}$ incubation in the presence or absence of PMA in AMs and Ms, and the basal RLMFI levels were the same in all three cell populations.

PMA stimulation resulted in a 110-fold increase in RLMFI in DHR-incubated PMNs, but no significant increases were observed during PMA stimulation in AMs and Ms (fig. 2). The basal RLMFI in Ms was four-fold and six-fold higher than that of AMs and PMNs $(\mathrm{p}<0.01)$, respectively.

Production of oxidants in subpopulations of alveolar macrophages

Following incubation with DHE, small AMs (fig. 1, region 1$)$ showed significantly $(\mathrm{p}<0.05)$ higher RLMFIs than the larger AMs (regions 2 and 3 ) after $1 \mathrm{~h}$ and $2 \mathrm{~h}$ of PMA stimulation (fig. 3).

As regards DCFH-DA-induced fluorescence, however, an opposite trend was observed, RLMFI being greatest in large AMs (fig. 1, regions 2 and 3 ) in unstimulated as well as in PMA-stimuiated cells $(\mathrm{p}<0.05)$.

After incubation with DHR, RLMFIs were similar in all three subpopulations of AM and neither incubation alone nor PMA stimulation had significant modulating effect on the formation of oxidants.

\section{Discussion}

In the present study, marked differences were demonstrated between blood leukocytes and AMs as regards capacity to increase intracellular oxidant formation upon PMA stimulation, i.e. PMNs $>\mathrm{Ms}>\mathrm{AMs}$. Further, significant differences were also demonstrated between small and large AMs with respect to oxidant formation. a)

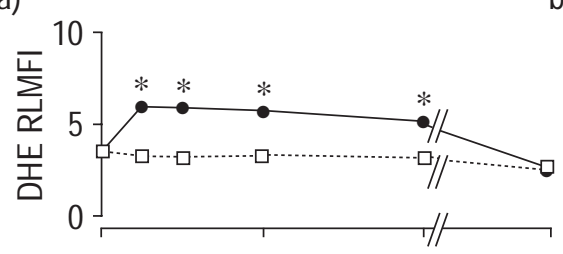

d)

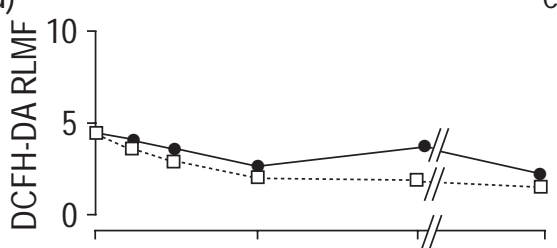

g)

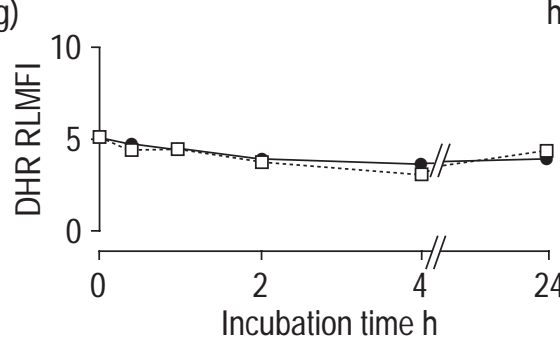

b)

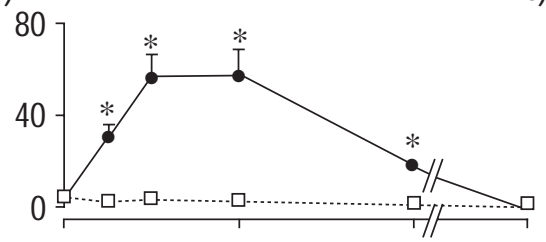

e)

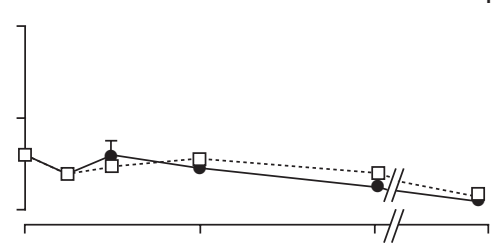

h)

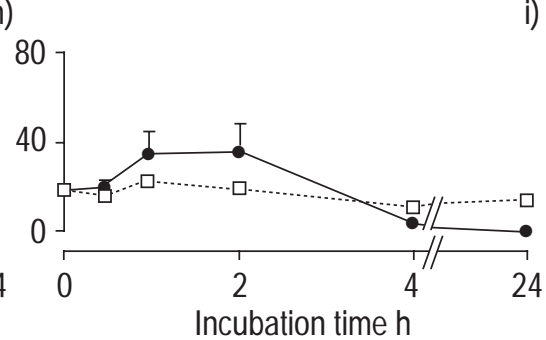

c)
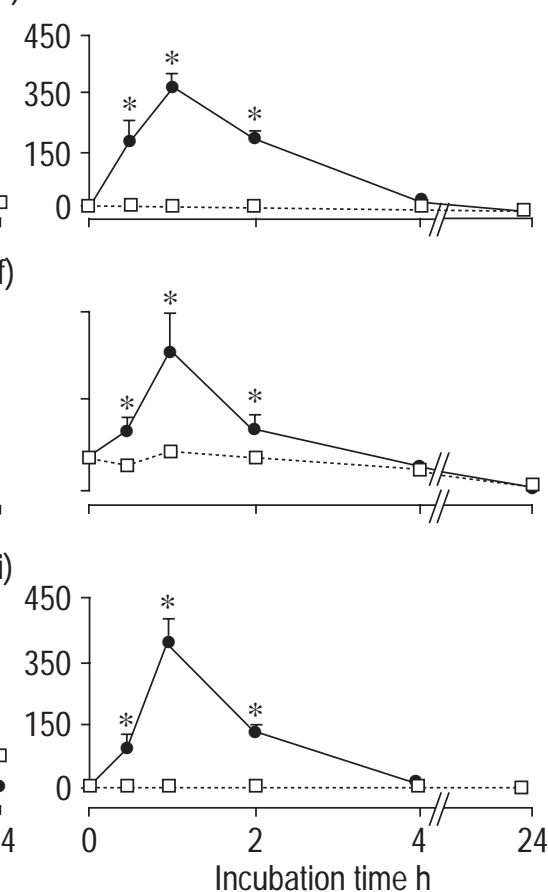

Fig. 2. - Relative linear median fluorescence intensity (RLMFI) after incubation with: a-c) dihydroethidium (DHE); d-f) 2, 7-dichlorofluorescein diacetate (DCFH-DA); and g-i) dihydrorhodamine 123 (DHR) in a, d, g) alveolar macrophages; b, e, h) moncytes; and c, f, i) polymorphonuclear neutrophils $(\mathrm{n}=6)$ in the presence $(\bullet)$ or absence $(\square)$ of phorbol myristate acetate (PMA) $\left(100 \mathrm{ng} \cdot \mathrm{mL}^{-1}\right)$. Values are given as mean \pm SEM. A value of 1 indicates no detectable specific fluorescence. $*$ : $\mathrm{p}<0.05$, PMA-stimulated versus unstimulated cells. 
It has previously been claimed that DHE, DCFH-DA and DHR indicate the production of mainly $\mathrm{O}_{2}{ }_{2}^{-}, \mathrm{H}_{2} \mathrm{O}_{2}$ and $\mathrm{ONOO}^{-}$, respectively [22-24]. Based on this assumption, the present demonstration of probe-related differences in fluorescence intensity indicates that AMs, Ms and PMNs possess significant differences in their production capacities for $\mathrm{O}_{2}{ }_{2}^{-}, \mathrm{H}_{2} \mathrm{O} 2$ and $\mathrm{ONOO}^{-}$. However, in the authors' opinion, the specificity of DHE, DCFH-DA and DHR in monitoring individual oxidants should be considered doubtful, at least until further evidence to this end has been gathered. It should also be emphasised that comparisons of oxidant levels in different cell types are valid only if DHE, DCFH-DA and DHR penetrate the cell membranes to a similar extent and if RLMFI is linearly related to the concentrations of the oxidants. These methodological problems were not the objective of the presented study, which, however, clearly illustrates the necessity of using different fluorescent probes when intracellular oxidant levels are examined by means of flow cytometry.

Conflicting results have been published regarding the oxidant production capacity of Ms and AMs. Some authors have reported similar ROS production capacity in Ms and AMs upon activation $[27,28]$, whereas others have demonstrated greater oxidation activity in AMs [29]. However, a weaker respiratory burst in resident macrophages compared to Ms has also been reported, as well as decreasing secretion of ROS when Ms mature to macrophages in vitro [30]. These latter data are in accordance with the present results, which are also supported by a series of reports in which $\mathrm{O}_{2}{ }^{-}$production was shown to be greater in high-density, i.e. small monocyte-like AMs compared to low-density AMs [14, 31-34]. In apparent contrast to this is the present finding that large cells, probably representing low-density AMs [16], had higher intracellular oxidant levels than small AMs, when monitored using fluorescence of oxidised DCFH. Dif- ferent methodology for estimating oxidant production, e.g. measuring either secreted or intracellular (as in this report) oxidants, may explain the divergent results.

It has been claimed that $\mathrm{HOCl}$ is the major oxidant generated by PMNs [35], but recently it was reported that activated PMNs and Ms predominantly generate $\mathrm{O}_{2}{ }_{2}^{-}[36]$. The present demonstration of equal oxidant production in activated PMNs when using two different probes (DHR and DHE) suggests that not only one oxidant predominates in activated PMNs, provided that DHR and DHE demonstrate mainly different oxidants. In accordance with these results are the observations of STRAUSz et al. [37], the ROS release per cell being higher in PMNs compared to AMs in BAL from patients with idiopathic pulmonary fibrosis (IPF). In that study, it was demonstrated that ROS production in AMs from IPF patients was markedly increased compared to that in control subjects. In contrast, the present study on AMs from healthy individuals showed only a very modest PMA-induced increase in oxidant production. This discrepancy between AMs from IPF patients and healthy persons may be explained by the effects of priming compounds, e.g. cytokines, in inflammatory diseases [3, 29, 38].

The present study demonstrates a significantly greater increase in production of oxidants in PMNs than in Ms upon PMA stimulation, particularly for those oxidants detected by DHE and DHR fluorescence. These results support the view that an association exists between oxidant injury mechanisms and the crucial role of PMNs in ARDS [19].

The relative contributions of alveolar macrophages, monocytes and polymorphonuclear neutrophils to the overall respiratory burst in lung inflammatory disorders probably varies for each specific disease [4], as indicated in studies in patients with adult respiratory distress syndrome, sarcoidosis and idiopathic pulmonary fibrosis
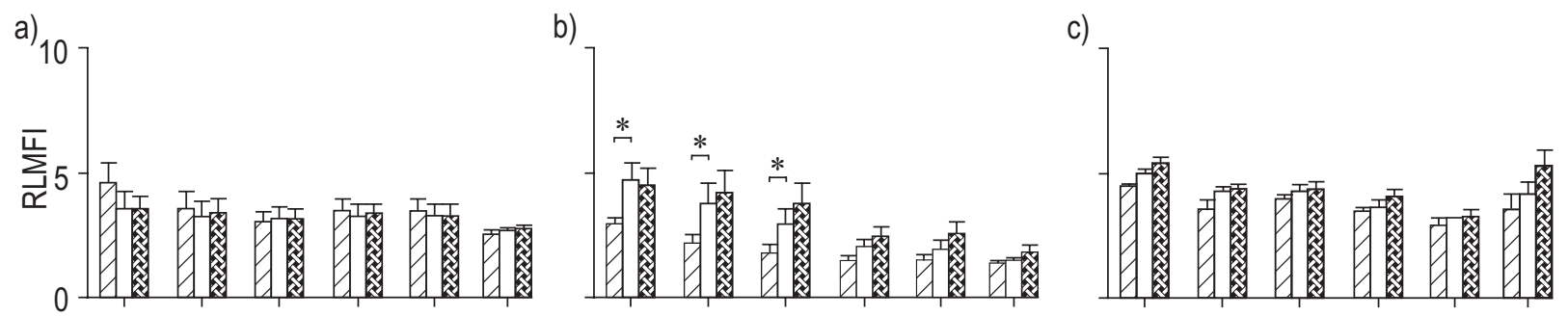

d)

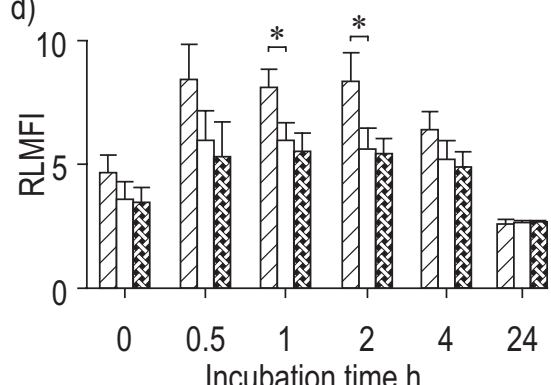

e)

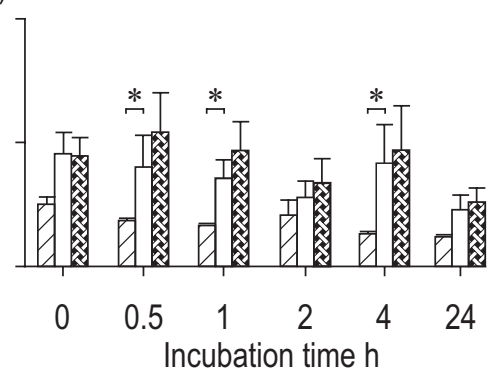

f)

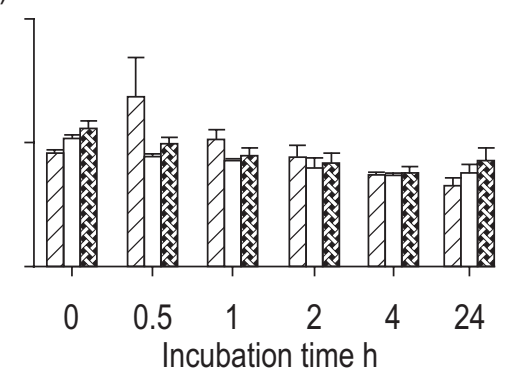

Fig. 3. - Relative linear median fluorescence intensity (RLMFI) after incubation with: a, d) dihydroethidium; b, e) 2, 7-dichlorofluorescein diacetate; and c, f) dihydrorhodamine 123 in a size-defined: a-c) unstimulated; and d-f) phorbol myristate acetate-stimulated (100 ng.mL $\left.{ }^{-1}\right)$ alveolar macrophages (AMs); $\mathbb{Z}$ : small AMs; $\square$ : intermediate AMs; $:$ large AMs. Values are given as mean \pm SEM. A value of 1 indicates no detectable specific fluorescence. *: $\mathrm{p}<0.05$, 
$[5,6,32,37,39]$ as well as in animal studies, using experimental models of lung injury [40, 41]. In conclusion, the present study clearly demonstrates that alveolar macrophages, monocytes and polymorphonuclear neutrophils posess significant differences in potential to increase their intracellular levels of oxidants upon stimulation. The results also suggest that the overall oxidative burden of the lung is critically dependent on the predominant inflammatory cell population, as well as on the activation state of the inflammatory cells.

Acknowledgements. The authors thank L.L. Haheim, (Life Insurance Companies' Institute for Medical Statistics, Oslo) for valuable statistical advice.

\section{References}

1. Lohmann-Matthes M-L, Steinmüller C, Franke-Ullmann G. Pulmonary macrophages. Eur Respir J 1994; 7: 1678 1689.

2. Maier KL. How the lung deals with oxidants. Eur Respir $J$ 1993; 6: 334-336.

3. Doelman CJA, Bast A. Oxygen radicals in lung pathology. Free Rad Biol 1990; 9: 381-400.

4. Schraufstätter IU, Cochrane CG. Oxidants: types, sources, and mechanisms of injury. In: Crystal RG, West JB, eds. The Lung: Scientific Foundations. Philadelphia, Raven Publishers, 1997; pp. 2251-2257.

5. Chabot F, Mitchell JA, Gutteridge JMC, Evans TW. Reactive oxygen species in acute lung injury. Eur Respir $J$ 1998; 11: 745-757.

6. Schaberg T, Rau M, Stephan H, Lode H. Increased number of alveolar macrophages expressing surface molecules of the CD11/CD18 family in sarcoidosis and idiopathic pulmonary fibrosis is related to the production of superoxide anions by these cells. Am Rev Respir Dis 1993; 147: 1507-1513.

7. Majori M, Vachier I, Godard P, Farce M, Bousquet J, Chanez P. Superoxide anion production by monocytes of corticosteroid-treated asthmatic patients. Eur Respir $J$ 1998; 11: 133-138.

8. Vachier I, Chanez P, Le Doucen C, Damon M, Descomps B, Godard P. Enhancement of reactive oxygen species formation in stable and unstable asthmatic patients. Eur Respir J 1994; 7: 1585-1592.

9. Miles AM, Bohle DS, Glassbrenner PA, Hansert B, Wink DA, Grisham MB. Modulation of superoxide-dependent oxidation and hydroxylation reactions by nitric oxide. $J$ Biol Chem 1996; 271: 40-47.

10. Ischiropoulos H, Zhu L, Beckman JS. Peroxynitrite formation from macrophage-derived nitric oxide. Arch Biochem Biophys 1992; 298: 446-451.

11. Kooy NW, Royall JA, Ye YZ, Kelly DR, Beckman JS Evidence for in vivo peroxynitrite production in human acute lung injury. Am J Respir Crit Care Med 1995; 151: $1250-1254$.

12. Haddad IY, Pataki G, Hu P, Galliani C, Beckman JS, Matalon S. Quantitation of nitrotyrosine levels in lung sections of patients and animals with acute lung injury. $J$ Clin Invest 1994; 94: 2407-2413.

13. Ischiropoulos $\mathrm{H}, \mathrm{Al}-$ Mehdi $\mathrm{AB}$, Fischer $\mathrm{AB}$. Reactive species in ischemic rat lung injury; contribution of peroxynitrite. Am J Physiol (Lung Cell Mol Physiol) 1995; 269: L158-L164.
14. Calhoun WJ, Reed HE, Moest DR, Stevens CA. Enhanced superoxide production by alveolar macrophages and air-space cells, airway inflammation, and alveolar macrophage density changes after segmental antigen bronchoprovocation in allergic subjects. Am Rev Respir Dis 1992; 145: 317-325.

15. Kuo HP, Yu CT. Alveolar macrophage subpopulations in patients with active pulmonary tuberculosis. Chest 1993; 104: 1773-1778.

16. Nakstad B, Lyberg T, Skjørten F, Boye NP. Subpopulations of human lung alveolar macrophages: ultrastructural features. Ultrastruct Pathol 1989; 13: 1-3.

17. Brannen AL, Chandler DB. Alveolar macrophage subpopulations' responsiveness to chemotactic stimuli. $\mathrm{Am} \mathrm{J}$ Pathol 1988; 132: 161-165.

18. Rothberger H, McGee MP, Lee T-K. Tissue factor activity. A marker of alveolar macrophage maturation in rabbits. Effects of granulomatous pneumonitis. J Clin Invest 1984; 73: 1524-1531.

19. Idell S, Cohen AB. Bronchoalveolar lavage in patients with the adult respiratory distress syndrome. Clin Chest Med 1985; 6: 459-471.

20. Crystal RG, Bitterman PB, Rennard SI, Hance AJ, Keogh BA. Interstitial lung diseases of unknown cause. Disorders characterized by chronic inflammation of the lower respiratory tract. New EngI J Med 1984; 310: 154166.

21. Hance AJ, Douchess S, Winchester RJ, Ferrans VJ, Crystal RG. Characterization of mononuclear phagocyte subpopulations in the human lung by using monoclonal antibodies: changes in alveolar macrophage phenotype associated with pulmonary sarcoidosis. J Immunol 1985 ; 134: 284-292.

22. Perticarari S, Presani G, Banfi E. A new flow cytometric assay for the evaluation of phagocytosis and the oxidative burst in whole blood. J Immunol Methods 1994; 170: 117-124.

23. Shapiro HM. Practical flow cytometry. 3rd Edn. New York, Wiley-Liss, John Wiley \& Sons Inc., 1995; pp. 318-319.

24. Kooy NW, Royall JA, Ischiropoulos H, Beckman JS. Peroxynitrite-mediated oxidation of dihydrorhodamine 123. Free Radic Biol Med 1994; 16: 149-156.

25. Haslam PL, Parker DJ, Townsend PJ. Increases in HLADQ, DP, DR and transferrin receptors on alveolar macrophages in sarcoidosis and allergic alveolitis compared with fibrosing alveolitis. Chest 1990; 97: 651-661.

26. Wassermann K, Subklewe M, Pothoff G, Banik N, SchellFrederick E. Expression of surface markers on alveolar macrophages from symptomatic patients with HIV infection as detected by flow cytometry. Chest 1994; 105 : 1324-1334.

27. Kienast K, Müller-Quernheim J, Knorst M, Lubjuhn S, Ferlinz R. In vitro study of human alveolar macrophage and peripheral blood mononuclear cell reactive oxygenintermediates release induced by sulfur dioxide at different concentrations. Lung 1994; 172: 335-345.

28. Kienast K, Knorst M, Lubjuhn S, Müller-Quernheim J, Ferlinz R. Nitrogen dioxide-induced reactive oxygen intermediates production by human alveolar macrophages and peripheral blood mononuclear cells. Arch Environment Health 1994; 49: 246-250.

29. Kemmerich B, Rossing TH, Pennington JE. Comparative oxidative microbicidal activity of human blood monocytes and alveolar macrophages and activation by recombinant gamma interferon. Am Rev Respir Dis 1987; 136: 266-270. 
30. Klebanoff SJ. Phagocytic cells: products of oxygen metabolism. In: Gallin JI, Goldstein W, Snyderman $\mathrm{R}$, eds. Inflammation: Basic principles and clinical correlates. New York, Raven Press Ltd., 1988; pp. 391444.

31. Holian A, Dauber JH, Diamond MS, Daniele RP. Separation of bronchoalveolar cells from the guinea pig on continuous gradients of Percoll: functional properties of fractionated lung macrophages. J Reticuloend Soc 1983; 33: 157-164.

32. Calhoun WJ, Salisbury SM. Heterogeneity in cell recovery and superoxide production in buoyant, density-defined subpopulations of human alveolar macrophages from healthy volunteers and sarcoidosis patients. J Lab Clin Med 1989; 114: 682-690.

33. Zeidler RB, Yarbro JW, Conley NS. Bleomycin increases superoxide production in the most active alveolar macrophage subpopulation. Int J Immunopharmac 1987; 9: 691-696.

34. Schaberg T, Klein U, Rau M, Eller J, Lode H. Subpopulations of alveolar macrophages in smokers and nonsmokers: relation to the expression of CD11/CD18 molecules and superoxide anion production. Am J Respir Crit Care Med 1995; 151: 1551-1558.

35. Domigan NM, Charlton TS, Duncan MW, Winterbourn CC, Kettle AJ. Chlorination of tyrosyl residues in pep- tides by myeloperoxidase and human neutrophils. J Biol Chem 1995; 270: 16542-16548.

36. Gillissen A, Bartling A, Schoen S, Schultze-Werninghaus G. Antioxidant function of ambroxol in mononuclear and polymorphonuclear cells in vitro. Lung 1997; 175: 235242.

37. Strausz J, Müller-Quernheim J, Steppling H, Ferlinz R. Oxygen radical production by alveolar inflammatory cells in idiopathic pulmonary fibrosis. Am Rev Respir Dis 1990; 141: 124-128.

38. Brown MA, Lantz RC, Sobonya R, Devine LC, Lentz LA, Lemen RJ. Aerosolized lipopolysaccharide increases pulmonary clearance of 99mTc-DTPA in rabbits. Am Rev Respir Dis 1992; 146: 1462-1468.

39. Sibille Y, Marchandise F-X. Pulmonary immune cells in health and disease: polymorphonuclear neutrophils. Eur Respir J 1993; 6: 1529-1543.

40. Gatti S, Faggioni R, Echtenacher B, Ghezzi P. Role of tumor necrosis factor and reactive oxygen intermediates in lipopolysaccharide-induced pulmonary oedema and lethality. Clin Exp Immunol 1993; 91: 456-461.

41. Tsuji C, Minhaz MU, Shioya S, Fukahori M, Tanigaki T, Nakazawa $\mathrm{H}$. The importance of polymorphonuclear leukocytes in lipopolysaccharide-induced superoxide anion production and lung injury: ex vivo observation in rat lungs. Lung 1997; 176: 1-13. 